Saudi Journal of Medicine

Abbreviated Key Title: Saudi J Med ISSN 2518-3389 (Print) |ISSN 2518-3397 (Online)

\title{
Socio-Demographic, Clinical and Biochemical Characteristics of Patients Living With Type 2 Diabetes and Hypertension Co-Morbidity Seen in the Medical Outpatient Clinic of the University of Portharcourt Teaching Hospital
}

\author{
Edeogu JU, Nwafor CE, Alikor CA*, Dodiyi -Manuel S, Unamba N, Odia OJ \\ Department of Internal Medicine, University of Portharcourt Teaching Hospital, Rivers State Nigeria
}

DOI: $10.36348 / \mathrm{sjm} .2020 . v 05 i 02.003$

| Received: 14.01.2020 | Accepted: 29.01.2020 | Published: 08.02.2020

*Corresponding author: Dr Alikor CA

Abstract

Background: The population of persons living with diabetes and hypertension is increasing worldwide. Despite this increment, data on this subgroup of patients is scarce. Objective: To study the socio-demographic, clinical and biochemical characteristics of patients living with type 2 diabetes and hypertension co-morbidity. Subject and methods: This is a cross-sectional study carried out at the cardiology unit of the department of Internal Medicine University of Portharcourt Teaching Hospital. One hundred and sixty adults18years and above living with hypertension and diabetes were recruited. 80 adults living with hypertension matched for age and sex served as control. Data on patient's age, sex, duration of hypertension, DM, family history of diabetes, hypertension, history of sedentary life style, alcohol consumption, peripheral neuropathy, smoking and ischemic heart disease, body mass index, waist circumference, blood pressure ,pulse pressure, fasting blood sugar, fasting lipid profile and serum electrolyte ,urea and creatinine were obtained. Results: The mean age of the cases was $57.51 \pm 9.1$ years. There were $60 \%$ females and $40 \%$ males among the cases. Family history of DM and hypertension were found in 81(50.6\%) and $107(66.9 \%)$ respectively. History of ischemic heart disease was positive in $63(39.4 \%)$ of the cases and positive in $40(50 \%)$ of the controls. The mean body mass index was statistically higher in the cases compared to the controls $\left(29.46 \pm 4.4 \mathrm{~kg} / \mathrm{m}^{2} \mathrm{vs} 26.66 \pm 4.40 \mathrm{~kg} / \mathrm{m}^{2} \mathrm{p}=0.022\right)$. The prevalence of sedentary life style was significantly higher in the cases than the controls 58(36.2\%) vs $19(23.8 \%) \mathrm{p}=0.001)$. The systolic BP and triglyceride of the cases and control were comparable. Mean e-EGFR was significantly lower in the cases than the controls $68.98 \pm 25.14 \mathrm{mls} / \mathrm{min}$ vs $88.33 \pm 28.94 \mathrm{ml} / \mathrm{min}$. Conclusion: Sedentary lifestyle, obesity and renal impairment were common in people living with hypertension diabetes co-morbidity. Ischemic heart disease based on history was less common.

Keywords: Socio-Demographic Clinical Biochemical Diabetes Portharcourt.

Copyright @ 2020: This is an open-access article distributed under the terms of the Creative Commons Attribution license which permits unrestricted use, distribution, and reproduction in any medium for non-commercial use (NonCommercial, or CC-BY-NC) provided the original author and source are credited.

\section{INTRODUCTION}

Hypertension is a common problem in people living with type 1 or type 2 diabetes. Its time course in relation to the duration of diabetes is different for both types of diabetes [1]. Among those with type $1 \mathrm{DM}$, the incidence of hypertension rises from $5 \%$ at 10years to $33 \%$ at 20years [1]. The findings are different for people with type2 DM. In a series of 3500 newly diagnosed type 2 diabetic patients, 39\% were already hypertensive [2]. Hypertension and DM are strongly associated with obesity and not surprisingly people living with hypertension and diabetes are at increased risk for cardiovascular disease and morbidity. This is due to coexistence of hypertension myocardial ischemia and specific diabetic cardiomyopathy termed "cardiotoxic triad". Early detection and treatment of hypertension and diabetes co-morbid features is particularly important to prevent cardiovascular disease and to minimize progression of renal disease and diabetic retinopathy [3]. It is therefore imperative that people living with hypertension and diabetes mellitus morbidity are studied systematically. The aim of this study is to study the clinical and biochemical characteristics of people living with hypertension and diabetes attending medical outpatient clinic of the University of Portharcourt teaching hospital.

\section{SUBJECTS AND METHODS}

Study population consisted of hypertensive type 2 diabetic subjects greater than 18years of age seen at the medical out- patient clinic or admitted into the medical ward of the hospital randomly selected. Data 
was obtained from subjects who were considered hypertensive diabetic on the basis of blood pressure $\geq 140 / 90 \mathrm{mmHg}$ and existing diagnosis or fasting blood sugar greater than $7.0 \mathrm{mmol} / \mathrm{l}$. An arm of control comprising 80 hypertensive patients attending medical outpatient clinic or admitted to the medical ward selected randomly and matched for age and sex were recruited.

Data obtained include age, sex, family history of DM and hypertension, history of ischemic heart disease and history of neuropathy using a structured questionnaire. The study subjects underwent clinical examination to determine weight, height, waist circumference, body mass index and waist-hip ratio. Pulse was counted for one minute assessing rate, rhythm, volume, character and synchrony.

Blood pressure was measured using accoson mecury sphygmomanometer to determine the brachial arterial systolic and diastolic blood pressure using the first and fifth korotkoff sounds respectively[4]. Two blood pressure measurements were taken measured 3 minutes apart and after 5minutes of rest with the arm at the heart level and the average recorded. Exercise, smoking, and caffeine were avoided at least 30 minutes prior to the blood pressure measurement. Hypertension was deemed present if BP is $\geq 140 / 90 \mathrm{mmHg}$ on at least 3 occasions or current use of antihypertensive agents [4]. The subjects were weighed without shoes and in light clothing on standard beam balance while height was measured to the nearest centimeter using a standiometer, subjects standing with feet together without shoes or head gear.

Body mass index was calculated and classified according to WHO as class normal weight (18.5$\left.24.9 \mathrm{~kg} / \mathrm{m}^{2}\right)$, overweight $\left(25-29.9 \mathrm{~kg} / \mathrm{m}^{2}\right)$ class 1 obesity $\left(30-34.9 \mathrm{~kg} / \mathrm{m}^{2}\right)$ class 2 obesity $\left(35-39.9 \mathrm{~kg} / \mathrm{m}^{2}\right)$ and morbid obesity $\left(\geq 40 \mathrm{~kg} / \mathrm{m}^{2}\right)[5]$. A venous blood sample was drawn and analyzed in the hematology chemical pathology laboratories of UPTH for plasma hemoglobin, fasting lipid profile, fasting plasma glucose.

Venopuncture was carried out and $10 \mathrm{mls}$ of fasting blood sample was drawn from each subject and hypertensive control between 7:30am and 8:30am, $2 \mathrm{mls}$ was put into fluoride oxalate bottle for FBG estimation, $5 \mathrm{mls}$ of which was put into lithium heparin bottle for assessment of lipid profile and serum electrolyte, urea, creatinine and uric acid, $3 \mathrm{mls}$ was put into EDTA bottle for haemoglobin estimation. Urinalysis was done to assay for protein using dipstick .Fasting lipid profile including triglyceride, total cholesterol, HDL, TG were measured using enzymatic method with a reagent from Atlas medical laboratories. Fasting HDL was measured with the precipitation method. LDL was calculated using the Fried-wald equation when the triglyceride level was less than $4.0 \mathrm{mmol} / \mathrm{dl}$ (LDL=TC(HDL+TG/2.2)[6].HbA1c was assessed using a bioRad laboratories $\mathrm{Ln} 2 \mathrm{it}^{\mathrm{R}}$ which is diabetic control and Complication Trial Calibrated. A pipette was used to obtain a drop of the participant's blood. This was then inserted into the cartridge and placed into the machine. The assay time was 10 mins and the result displayed in $\%$ on the machine screen. Diabetes was diagnosed on the basis of presence of symptoms of DM- Polyuria, polydypsia with random blood glucose $>11.1 \mathrm{mmol} / \mathrm{L}[7]$ or previously diagnosed patients.

\section{RESULTS}

A total 240 subjects participated in the study of which 160 were 160 constituted participants with both hypertension and diabetes mellitus (cases) and 80 participants with hypertension only (control). There were more female than male in the ratio of $1.5: 1$ as $96(60 \%)$ were females and $64 \%$ (40) were males. Among hypertensive controls there was slight female preponderance $42(52.5 \%)$ and $38(47.5 \%)$ were males giving a ratio of 1.6:1.The ages of the cases ranged between39-87 with a mean age of $57.51 \pm 9.18$ years. The ages of the hypertensive control controls ranged between35-79years with a mean age of $55.90 \pm 12.15$ years. BMI was significantly higher in the cases than in the controls $29.46 \pm 5.64 \mathrm{~kg} / \mathrm{m} 2$ vs $27.83 \pm 4.42 \mathrm{~kg} / \mathrm{m}^{2}$. The mean diastolic BP was significantly higher in the controls than in the cases $87.29 \pm 11.0 \mathrm{mmHg}$ vs $83.41 \pm 9.44 \mathrm{mmHg}$. The mean pulse pressure of the cases was significantly higher in the cases than in the controls $53.9 \pm 13.85 \mathrm{mmHg}$ vs $68.98 \pm 25.14 \mathrm{mmHg}$. Family history of hypertension was comparable in both the cases and the controls. The clinical characteristics of the cases and controls are shown in table $1 \mathrm{a}$ and $1 \mathrm{~b}$ below. Hb concentration of the cases ranged from $7-15 \mathrm{~g} / \mathrm{dl}$ with a mean of $11-65$ $\pm 1.65 \mathrm{~g} / \mathrm{dl}$ while that of the control ranged from 10 $16 \mathrm{~g} / \mathrm{dl}$ with a mean of $13.03 \pm 1.33 \mathrm{~g} / \mathrm{dl}$. There was statistically significant difference between the mean hemoglobin concentration of the cases and the controls. Comparing the mean e-GFR of the cases and controls showed statistically significant higher mean e-GFR in the controls than in the cases $88.33 \pm 28.94 \mathrm{mls} / \mathrm{min}$ vs $68.98 \pm 25.14 \mathrm{mls} / \mathrm{min}$. The mean total cholesterol was significantly lower in the cases than in the controls $4.57 \pm 1.25 \mathrm{mmol} / 1$ vs $5.41 \pm 1.24 \mathrm{mmol} / 1$. The mean triglyceride of both the cases and controls were comparable $1.8 \pm 0.47 \mathrm{mmol} / \mathrm{l}$ vs $1.23 \pm 0.55 \mathrm{mmol} / 1$. The mean HDL was statistically higher in the controls than in the cases $0.90 \pm 0.19 \mathrm{mmol} / 1$ vs $1.41 \pm 0.69 \mathrm{mmol} / 1$. The laboratory characteristics of the cases and controls are compared in table 2 below. 
Table-1: Socio-demographic characteristics of the study population

\begin{tabular}{|l|l|l|c|}
\hline \multicolumn{1}{|c|}{ VARIABLES } & \multicolumn{1}{c|}{$\begin{array}{c}\text { Cases } \\
\mathbf{N = 1 6 0}(\boldsymbol{\%})\end{array}$} & $\begin{array}{c}\text { Hypertensive control } \\
\mathbf{N = 8 0}(\mathbf{\%})\end{array}$ & $\mathbf{P}$ \\
\hline Age(years) & & & \\
$30-39$ & $2(1.2)$ & $8(10.0)$ & 0.323 \\
$40-49$ & $22(13.8)$ & $20(25.0)$ & \\
$50-59$ & $74(46.2)$ & $20(25.2)$ & \\
$60-69$ & $48(30.0)$ & $20(25.0)$ & \\
$70-79$ & $8(5.0)$ & $12(15.0)$ & \\
$80-89$ & $6(3.8)$ & $0(0.0)$ & 0.453 \\
Sex & & & \\
Male & $64(40)$ & $38(37.5)$ & 0.513 \\
female & $96(60)$ & $42(52.5)$ & $0.001 *$ \\
\hline Smoking & $6(3.8)$ & $5(6.2)$ & 0.625 \\
\hline Family History of DM & $81(50.6)$ & $58(72.5)$ & 0.691 \\
\hline Family History of HTN & $107(66.9)$ & $56(70.0)$ & \\
\hline Alcohol intake & $21(13.1)$ & $12(15.0 \%)$ & \\
\hline Sedentary Lifestyle & $58(36.2)$ & $19(23.8)$ & \\
& & & \\
\hline
\end{tabular}

\section{KEY:}

Cases $=$ Patients with hypertension and diabetes

Controls=Patients with hypertension

$\mathrm{P}=\mathrm{P}$ value for cases versus hypertensive controls.

Table-2: Clinical characteristics of the study population

\begin{tabular}{|l|l|l|l|}
\hline \multicolumn{1}{|c|}{ VARIABLE } & Cases(n=160) & Hypertensive controls $(\mathbf{n = 8 0})$ & P \\
\hline & Mean \pm SD & Mean \pm SD & \\
\hline BMI $(\mathrm{kg} / \mathrm{m} 2)$ & $29.46 \pm 5.64$ & $26.66 \pm 4.40$ & $0.022^{*}$ \\
\hline WC $(\mathrm{cm})$ & $100.23 \pm 10.54$ & $97.78 \pm 12.10$ & 0.108 \\
\hline WHR & $1.0 \pm 0.09$ & $0.95 \pm 0.07$ & $0.001^{*}$ \\
\hline SBP $(\mathrm{mmHg})$ & $137.54 \pm 17.14$ & $136.26 \pm 20.21$ & 0.599 \\
\hline DBP $(\mathrm{mmHg})$ & $83.41 \pm 9.44$ & 87.2911 .00 & $0.001 *$ \\
\hline PR b/min & $83.78 \pm 11.55$ & 76.909 .57 & $0.001^{*}$ \\
\hline Pulse pressure $(\mathrm{mmHg})$ & $53.59 \pm 13.85$ & 49.0013 .08 & $0.014^{*}$ \\
History of Neuropathy & $118(73.8 \%)$ & $24(30.0 \%)$ & $0.001^{*}$ \\
History of ischaemic heart disease & $63(39.4 \%)$ & $40(50 \%)$ & $0.117 *$ \\
\hline
\end{tabular}

Key:

Cases $=$ Patients with hypertension and diabetes

Controls=Patients with hypertension

$\mathrm{P}=\mathrm{P}$ value for Cases versus Hypertensive controls

Table-2: Laboratory characteristics of the study population

\begin{tabular}{|l|l|l|c|}
\hline & Cases(n=160) & Hypertensive controls(n=80) & P \\
\hline VARIABLES & MEAN \pm SD & MEAN \pm SD & \\
\hline FBS $(\mathrm{mmol} / \mathrm{L})$ & $8.24 \pm 2.85$ & $5.03 \pm 1.07$ & $0.001^{*}$ \\
\hline $\mathrm{Hb}(\mathrm{g} / \mathrm{dl})$ & $11.65 \pm 1.59$ & $13.03 \pm 1.33$ & $0.001^{*}$ \\
\hline EGFR (mls/min) & $68.98 \pm 25.14$ & $88.33 \pm 28.94$ & $0.001^{*}$ \\
\hline SUA (micromo/l) & $358.01 \pm 91.25$ & $323.74 \pm 88.79$ & $0.020^{*}$ \\
\hline TCH (mmol/L) & $4.57 \pm 1.25$ & $5.41 \pm 1.24$ & $0.001^{*}$ \\
\hline TG $(\mathrm{mmol} / \mathrm{L})$ & $1.18 \pm 0.47$ & $1.23 \pm 0.55$ & 0.733 \\
\hline HDL mmol/L & $0.90 \pm 0.19$ & $1.41 \pm 0.69$ & $0.036^{*}$ \\
\hline LDL mmol/L & $3.26 \pm 0.69$ & $3.15 \pm 1.48$ & $0.001^{*}$ \\
\hline HbAlc(\%) & $7.54 \pm 0.40$ & $5.02 \pm 0.66$ & $0.001^{*}$ \\
\hline
\end{tabular}

LEGEND: Data expressed as mean \pm standard deviation, FBS =fasting blood sugar, Hb=Hemoglobin concentration, $\mathrm{TCH}=$ Total cholesterol, $\mathrm{TG}=$ Triglyceride, $\mathrm{HDL}=$ High density lipoprotein, LDL=low density lipoprotein, HbAlc=Glycated Hemoglobin, eGFR=Estimated Glomerular filtration Rate, DM=Diabetes,

Cases $=$ patients with hypertension and diabetes

Controls=Patients with hypertension

$\mathrm{P} 1=$ Cases versus Hypertensive controls. 


\section{DISCUSSION}

This study was a cross -sectional study of 160 patients living with hypertension and diabetes mellitus (cases) and 80 patients with hypertension (controls) matched for age and sex.

Significant smoking was comparable across the cases and controls $3.8 \%$ vs $6.2 \%$. This was far lower than that reported in the LIFEstudy [8].This is not surprising considering the fact that high prevalence of smoking has been reported in the Western word [9]. Alcohol intake was slightly higher among the hypertensive controls than in the cases $15 \%$ vs $13.8 \%$. This was similar to that documented by Giovani de Simone et al.[10]This can be explained by more consciousness of people living with both hypertension and diabetes co-morbidity to healthy lifestyle. The proportion of cases with family of DM was lower than in the controls. The reason for this is not readily apparent in this study. It is an established fact that both hypertension and DM run in families [11]. More of the cases had a sedentary lifestyle than the controls $36.2 \%$ vs $23.8 \%$.Another study documented similar finding [11]. The proportion of cases with history of ischemic heart disease was lower than the cases $39.4 \% \mathrm{vs}$ $50 \%$.This can be explained by the concept of silent ischemia common in diabetic patients [12]. The BMI was significantly higher in the cases than in the controls with a mean of $29.46 \pm 5.64 \mathrm{~kg} / \mathrm{m}^{2}$. Anderson et al. [13] Hilderbrand et al. [8] documented significantly higher BMI in hypertensive diabetic cases than hypertensive controls similar to this study. Obesity is a common comorbidity in hypertension and type 2 DM [14]. This study showed that systolic blood pressure was comparable across cases and control137.26 $\pm 17.40 \mathrm{mmHg}$ vs $136.26 \pm 20.21 \mathrm{mmHg}$. On the contrary mean diastolic blood pressure was lower in the cases compared to the hypertensive controls $83.41 \pm 9.44 \mathrm{mmHg}$ vs $.29 \pm 11 \mathrm{mmHg}$. This implies wider pulse pressure which can be explained by increased arterial stiffness induced by DM and accelerated steady loss of aortic compliance induced by hypertension. Other investigators found similar trend $[15,16]$. The mean systolic blood pressure documented by Danbauchi et al. [17] and Hindabrandt et al. [8] were higher than that found in this study. The reason for the difference in the mean of the BP as documented by Danbauchi was probably exclusion of overt heart failure in their study.

The cases had a lower e-GFR compared to the controls $68.98 \pm 25.14 \mathrm{mls} / \mathrm{min}$ vs $88.33 \pm 28.94 \mathrm{ml} / \mathrm{min}$. This corroborates the fact that diabetes mellitus act additively impairing renal function. Similar differential pattern was found by other investigators [8]. The mean total cholesterol was higher in the hypertensive control compared with the cases. The reason for higher mean total cholesterol in the cases may be due to the fact that people living with hypertension and diabetes are more likely to be more dietary and drug adherent than hypertensive patients [18]. This finding is in agreement with that found by Hindabrandt et al. [8]. Triglyceride was comparable across the cases and controls. This is consistent with that reported in Sokoto, North-West Nigeria by Isiezuo et al.[19]. The cases had lower hemoglobin concentration compared to the cases $11.65 \pm 1.59 \mathrm{~g} / \mathrm{dl}$ vs $13.03 \pm 1.59 \mathrm{~g} / \mathrm{dl}$. This supports the fact that hypertension diabetes comorbidity accelerates renal impairment accounting for anemia in this sub-set of patients.

In conclusion, our study showed that, obesity, renal impairment and sedentary lifestyle were common in people living with type 2 diabetes mellitus and hypertension co-morbidity. Ischemic heart disease based on history of typical chest pain in this study is less common. These multiple morbidities place this subset of patients at higher cardiovascular risk. Therefore appropriate measures should be put in place to address these risk factors beyond hypertension and diabetes control.

\section{REFRENCES}

1 Epstein, M., \& Sowers, J. R. (1992). Diabetes mellitus and hypertension. Hypertension, 19(5), 403-418.

2 Turner, R., Holman, R., Matthews, D., Bassett, P., Coster, R., Stratton, I., \& Manley, S. (1993). Hypertension in diabetes study (Hds). 1. Prevalence of hypertension in newly presenting Type-2 diabetic-patients and the association with risk-factors for cardiovascular and diabetic complications. Journal of hypertension, 11(3).

3 Gæde, P., Vedel, P., Parving, H. H., \& Pedersen, O. (1999). Intensified multifactorial intervention in patients with type 2 diabetes mellitus and microalbuminuria: the Steno type 2 randomised studies. The Lancet, 353(9153), 617-622.

4 Chobanian, A. V., Bakris, G. L., Black, H. R., Cushman, W. C., Green, L. A., Izzo Jr, J. L., ... \& Roccella, E. J. (2003). The seventh report of the joint national committee on prevention, detection, evaluation, and treatment of high blood pressure: the JNC 7 report. Jama, 289(19), 2560-2571.

5 WHO. (2008). Waist circumference and waist-hip ratio: Report of a WHO expert consultation. World Heal Organ, 64, 8-11.

6 World Health Organization. (2011). Waist circumference and waist-hip ratio: report of a WHO expert consultation, Geneva, 8-11 December 2008.

7 Marathe, P. H., Gao, H. X., \& Close, K. L. (2017). American D iabetes A ssociation $\mathrm{S}$ tandards of $\mathrm{M}$ edical C are in D iabetes 2017. Journal of diabetes, 9(4), 320-324.

8 Hildebrandt, P., Wachtell, K., Dahlöf, B., Papademitriou, V., Gerdts, E., Giles, T., ... \& Devereux, R. B. (2005). Impairment of cardiac function in hypertensive patients with Type 2 
diabetes: a LIFE study. Diabetic medicine, 22(8), 1005-1011.

9 Loehr, L. R., Rosamond, W. D., Chang, P. P., Folsom, A. R., \& Chambless, L. E. (2008). Heart failure incidence and survival (from the Atherosclerosis Risk in Communities study). The American journal of cardiology, 101(7), 10161022.

10 De Simone, G., Devereux, R. B., Chinali, M., Best, L. G., Lee, E. T., Galloway, J. M., \& Resnick, H. E. (2007). Prognostic impact of metabolic syndrome by different definitions in a population with high prevalence of obesity and diabetes: the Strong Heart Study. Diabetes care, 30(7), 1851-1856.

11 Cheung, C. Y., Tso, A. W., Cheung, B. M., Xu, A., Ong, K. L., Law, L. S., ... \& Lam, K. S. (2011). Genetic variants associated with persistent central obesity and the metabolic syndrome in a 12-year longitudinal study. European journal of endocrinology, 164(3), 381.

12 Jacqueminet, S., Barthélémy, O., \& Le Feuvre, C. (2010). Screening of silent myocardial ischemia in type 2 diabetic patients: a randomized trial comparing isotopic and echocardiographic stress tests. Diabetes Care, 33(6), e79.

13 Andersen, N. H., Poulsen, S. H., Poulsen, P. L., Knudsen, S. T., Helleberg, K., Hansen, K. W., ... \& Mogensen, C. E. (2005). Left ventricular dysfunction in hypertensive patients with type 2 diabetes mellitus. Diabetic medicine, 22(9), 12181225.

14 Barr, E. L., Cameron, A. J., Balkau, B., Zimmet, P. Z., Welborn, T. A., Tonkin, A. M., \& Shaw, J. E. (2010). HOMA insulin sensitivity index and the risk of all-cause mortality and cardiovascular disease events in the general population: the
Australian Diabetes, Obesity and Lifestyle Study (AusDiab) study. Diabetologia, 53(1), 79-88.

15 Wagner, G. S., Macfarlane, P., Wellens, H., Josephson, M., Gorgels, A., Mirvis, D. M., \& Gettes, L. S. (2009). AHA/ACCF/HRS recommendations for the standardization and interpretation of the electrocardiogram: part VI: acute ischemia/infarction a scientific statement from the American Heart Association Electrocardiography and Arrhythmias Committee, Council on Clinical Cardiology; the American College of Cardiology Foundation; and the Heart Rhythm Society Endorsed by the International Society for Computerized Electrocardiology. Journal of the American College of Cardiology, 53(11), 1003-1011.

16 Palmieri, V., Bella, J. N., Arnett, D. K., Liu, J. E., Oberman, A., Schuck, M. Y., ... \& Devereux, R. B. (2001). Effect of type 2 diabetes mellitus on left ventricular geometry and systolic function in hypertensive subjects: Hypertension Genetic Epidemiology Network (HyperGEN) study. Circulation, 103(1), 102-107.

17 Palmieri, V., Bella, J. N., Arnett, D. K., Liu, J. E., Oberman, A., Schuck, M. Y., ... \& Devereux, R. B. (2001). Effect of type 2 diabetes mellitus on left ventricular geometry and systolic function in hypertensive subjects: Hypertension Genetic Epidemiology Network (HyperGEN) study. Circulation, 103(1), 102-107.

18 Davis, J. W., Fujimoto, R. Y., Chan, H., \& Juarez, D. T. (2011). Adherence with lipid-lowering, antihypertensive, and diabetes medications. Am J Pharm Benefits, 3(3), 165-71.

19 Marley, J. (1989). Lifestyle intervention in hypertension. The Practitioner, 233(1468), 661663. 